\title{
Relationships between Personal and Collective Place Identity and Well-Being in Mountain Communities
}

\author{
Igor Knez ${ }^{1 *}$ and Ingegärd Eliasson ${ }^{2}$ \\ ${ }^{1}$ Department of Social Work and Psychology, University of Gävle, Gävle, Sweden, ${ }^{2}$ Department of Conservation, University \\ of Gothenburg, Göteborg, Sweden
}

The aim was to investigate the relationships between landscape-related personal and collective identity and well-being of residents living in a Swedish mountain county $(N=850)$. It was shown that their most valued mountain activities were viewing and experiencing nature and landscape, outdoor recreation, rest and leisure, and socializing with friends/family. Qualitative analyses showed that the most valued aspects of the sites were landscape and outdoor restoration for personal favorite sites, and tourism and alpine for collective favorite sites. According to quantitative analyses the stronger the attachment/closeness/belonging (emotional component of place identity) residents felt to favorite personal and collective sites the more well-being they perceived when visiting these places. Similarly, the more remembrance, thinking and mental travel (cognitive component of place identity) residents directed to these sites the more well-being they perceived in these places. In both types of sites well-being was more strongly predicted by emotional than cognitive component of place-identity. All this indicates the importance of person-place bonds in beneficial experiences of the outdoors, over and above simply being in outdoor environments.

University of Tampere, Finland

Reviewed by:

Elizabeth K. Nisbet,

Trent University, Canada Eleanor Ratcliffe,

University of Tampere, Finland

${ }^{*}$ Correspondence:

lgor Knez igor.knez@hig.se

Specialty section:

This article was submitted to Environmental Psychology, a section of the journal

Frontiers in Psychology

Received: 08 November 2016 Accepted: 12 January 2017 Published: 31 January 2017

Citation:

Knez I and Eliasson I (2017)

Relationships between Personal and Collective Place Identity and Well-Being in Mountain Communities. Front. Psychol. 8:79. doi: 10.3389/fpsyg.2017.00079
Keywords: mountain, cultural ecosystem services, place-identity, well-being

\section{INTRODUCTION}

Identification with landscape as a cultural ecosystem service and its relation to human wellbeing has been recognized by Millenium Ecosystem Assessment [MA] (2005). Identity, heritage values, spiritual services, esthetic appreciation of natural and cultivated landscapes, recreation, and tourism are the categories of cultural ecosystem services that are provided by landscapes (Millenium Ecosystem Assessment [MA], 2005). The link between identity and well-being has, however, not as yet been fully addressed. Above all, because the concept of ecosystem services is primarily based on natural and economic science paradigms (Daily et al., 2009; Schaich et al., 2010; Tengberg et al., 2012) not including cultural ecosystem services per se (Chan et al., 2012; Hernández-Morcillo et al., 2013). Hence, more research is needed especially on the links between biological ecosystem outcomes, cultural landscape issues (Gee and Burkhard, 2010), health and well-being (Sandifer et al., 2015); a concern that is indicated in, for example, the European Landscape Convention [ELC] (2000).

\section{Landscape-Related Identification}

Definitions of landscape include not only objective natural characteristics (Turner, 1989), but also subjective human views, perceptions, identifications and memories (Knez, 2006; Knez and Thorsson, 2008; Lewicka, 2008; Stobbelaar and Pedroli, 2011). We evolve personal and collective 
ties toward landscapes, meaning that sites encompass not only physical and spatial parameters but also psychological, social, historical, religious, moral, health and cultural connotations (Graumann, 2002; Knez, 2005, 2013, 2016a; Knez et al., 2009; Knez et al., 2013; Lachowycz and Jones, 2013; Gunnarsson et al., 2016; Ode Sang et al., 2016). Culture is to society what memory is to individuals (Triandis, 1994), involving traditions and practices regarding how we perceive and comprehend physical surroundings and ourselves (Canter, 1997; Knez and Thorsson, 2006).

Accordingly, neither the individual nor the collective is placeless (Millenium Ecosystem Assessment [MA], 2005; European Landscape Convention [ELC], 2000). We anchor our existence in physical places, meaning that places serve to "situate one's memorial life" (Casey, 2000 p. 184). In line with this, place-related cognitions have been shown to comprise both personal (Knez, 2006; Taylor, 2010) and collective information (Lewicka, 2008) operating as autobiographical memory aids in self formation (Knez, 2014). This means that natural sites can act as reminders of important experiences and occurrences, by which we uphold and consolidate personal and collective types of identification (Wang, 2008; Wheeler, 2014).

Collective identity is linked to "group membership, group processes and intergroup behavior," and personal identity is associated with "close personal relationships and idiosyncratic attributes" (Hogg, 2006, p. 463). The type of identity of primary interest here is personal and collective knowledge apportioned across declarative memory as autobiographical memory (Kihlstrom and Klein, 1994); a self-related memory (Conway, 2005) resulting in "feeling that we are re-living our past" (Klein, 2013, p. 3). This type of cognizance is phenomenologically characterized as a life story (Fivush, 2008), involving several context-specific selves (McConnell, 2011; Knez, 2014, 2016b).

One such self is landscape-related identification (Stobbelaar and Pedroli, 2011), a place-related self, containing emotional and cognitive processes accounting for the experience of favorite personal and/or collective places respectively (Knez, 2014). Consistent with, for example, James (1890/1950), Tulving (2002), Conway et al. (2004), Klein et al. (2004), and Knez (2014) suggested a role for the cognitive processes of mental temporality, coherence, correspondence, reflection, and agency, as well as a role for the emotional process of attachment/closeness/belonging (Korpela, 2012) in place-related identification; accounting for the phenomenon of place-related self.

According to Knez (2014) place-related attachment, in agreement with Ainsworth et al. (1978) concept of secure attachment, includes a dimension of closeness/belonging (an emotional component of people-place bonding). Wang (2006) showed that earliest childhood memories were cued by the words mother and surrounding, suggesting an early development of the emotional component of attachment/closeness/belonging to a person and a site. Accordingly, this suggests that our personal and collective favorite places might operate as organizational structures in the autobiographical memory; that is, as chapters in a life story (Thomsen, 2009) clustering our personal and collective memories related to personal and collective favorite places respectively. Furthermore and giving that we remember better events that are emotionally processed than those that are not (Canli et al., 2000), Knez (2014) proposed and showed that a favorite place might be easier recalled due to its emotional information.

The model of a place-related self is conceptualized and operationalized in line with the view that: (1) "we are what we remember," and (2) a stable and healthy self encompasses processes of mental temporality, coherence, correspondence, reflection, agency, and attachment/closeness/belonging (Klein et al., 2004; Wang, 2006). This suggests that a place-related self is a higher-order construct (Stajkovic, 2006) capturing basic psychological processes grounding the relationship between a physical place and the self. Thus, the place-related self is conceptualized as a knowledge structure (Kihlstrom and Klein, 1994) resulting in a personal autobiographical experience of "my place" (Knez, 2014) as opposed to, for example, the construct of ecological self, accounting for the link between an environmentally responsible behavior and a world view (Bragg, 1996). (See also, for example, Neisser (1988) and Leary and Tangney (2003) for a discussion about different types of self and identity constructions in psychology.)

In the words of Knez (2014, p. 186): “...physical places and time position -anchor- one's reminiscence by forming psychological person-place ties, emotional and cognitive bonds that conduct the psychological agent toward physical places and time as the organizing formats for its personal memory... A place-related self is, thus, assumed to be a substructure of the self, emerging when we cogitate about our lives, when our self-representations are online, triggering streams of noesesways of knowing about ourselves." In consequence, this brings an additional theoretical position regarding the phenomenon of person-place ties than the more traditional ones of sense of place (Jorgensen and Stedman, 2001), place attachment (Scannell and Gifford, 2010), and place identity (Droseltis and Vignoles, 2010) considering, for example, person-place-bondingdimensions of identity and dependence to be integral parts of attachment (Brown and Raymond, 2007) or as separate dimensions (Jorgensen and Stedman, 2006).

In view of that, and as an example, by revealing a piece of my personal story, I have across time evolved an attachment/closeness/belonging toward a small place (Axmar) on the Swedish east coast (a place of mine) where I have a cottage. This place and its surrounding sea landscapes have grounded my landscape-related identification (conceptual and personal knowledge of me as cottage owner and user of its surroundings, including different types of emotional, cognitive and behavioral experiences). Reflecting upon these involvements of mine (agency) I remember the date and the time of day (inner temporality) when I bought this cottage (coherence in my landscape identification). As a consequence of all this and at this precise moment, I am thinking of the coming weekend when I will visit this site for some rest, leisure and outdoor recreation (an accurate correspondence with my ongoing landscape identification).

This proposes that we do not only cognize (processes of coherence, correspondence, reflection, inner temporality, and 
agency) about places in our life but we also emotionally invest (process of attachment/closeness/belonging) in these places (Marris, 1982). In other words: "Natural or semi-natural features of the environment are often associated with the identity of an individual, a community, or a society. They provide experiences shared across generations, as well as settings for communal interactions important to cultural ties" (Daniel et al., 2012 p. 8814). This suggests that both natural and cultural values are important for our personal and collective memory and heritage (Lowenthal, 2005; Aplin, 2007). As pointed out by Erll (2011, p. 13): "Acts of cultural remembering seem to be an element of human's fundamental anthropological make-up, and the history of creating shared heritage and thinking about memory can be traced to antiquity, for example to Homer, Plato, and Aristotle."

\section{Landscape-Related Well-Being}

On his tour of Lapland (northern part of Sweden) in 1732, Carl von Linné suggested a link between the natural scenery and wellbeing. In ancient Greece and Rome, as well as in many other cultures and religions, an archetypical landscape (such as the Biblical Garden of Eden) was/is associated with a supreme type of life (Thompson, 2011). Transcendent experiences (positive affect associated with a sense of timelessness) have also been shown to associate with natural environments (Laski, 1961; Williams and Harvey, 2001; Park et al., 2011). This therapeutic use of nature, therapeutic associations between nature and well-being including feelings of solitude and aesthetical values (Russell, 2012) are of course also portrayed in works of fiction, such as in Thomas Mann's The Magic Mountain containing impressions and images of "pure Alpine air and magnificent mountain landscapes" (Gesler, 2000, p. 126), and in self-biographical reflections of for example "Throughout my childhood, I always felt drawn to a mountain in the heart of Alaska which the Athabaskan Indians call Denali, The Great One ... Now, years later, I still recall the many transcendent experiences during my ascent of this tallest mountain in North America." (Hébert, 2014, p. 27), and "When I am lonely the mountains call me" (Griffin-Pierce, 1997 p. 1).

In line with this, many studies have indicated health and well-being benefits of the natural environment for humans (Lachowycz and Jones, 2013; Bratman et al., 2015), such as positive effects of nature on physiological, psychological, social and cultural variables (Abraham et al., 2010; Bowler et al., 2010; Hartig et al., 2011; Carrus et al., 2015; Sandifer et al., 2015). Theoretical models have in particular drown on emotional and aesthetical (Ulrich, 1983), and cognitive explanations for naturerelated restoration (Kaplan, 1995). Some have also indicated geographical inequalities in health (e.g., Bolam et al., 2006). In parallel with Millenium Ecosystem Assessment [MA]'s 2005 definition of cultural ecosystem services and their relation to human well-being several findings have shown that different levels of nature engagement (viewing nature, presence of nature, participation and involvement with nature) provide health benefits to humans (Pretty, 2004; Pretty et al., 2005). However, previous research (e.g., Hartig et al., 2011; Clayton, 2012) does not tell us much about the link between identity and memory we address to personal and collective favorite places and the wellbeing we experience when visiting these sites (e.g., Tuan, 1977; Gallagher, 1994; Knez, 2014).

In addition, the relation between the self/identity and the nature has been previously operationalized into several types of scales measuring phenomena of, for example, inclusion of nature in the self (Schultz, 2002), connectedness to nature (Mayer and Frantz, 2004), and connectivity to nature (Dutcher et al., 2007). Some previous research has moreover indicated relationships between restorative sites and person-place bonding (Korpela, 1989; Scannell and Gifford, 2010; Pretty et al., 2015), but no studies, as far we know, have investigated the links between landscape-related personal and collective identity (cultural ecosystem services as defined by Millenium Ecosystem Assessment [MA], 2005) and well-being in residents living in a mountain county; as provocatively stated by Grêt-Regamey et al. (2012) in their review of 155 studies on mountain ecosystem services: "Mountain Ecosystem Services: Who Cares?"

\section{Aims and Hypotheses}

The aim of this study was, thus, to investigate residents' mountain landscape-related personal and collective identity (involving emotional and cognitive processes) and well-being. In line with previous research on the positive relations between nature and health and well-being (Abraham et al., 2010; Bowler et al., 2010; Hartig et al., 2011; Sandifer et al., 2015) and the Millenium Ecosystem Assessment [MA] (2005) prediction of a positive link between cultural ecosystem services of identity and well-being, our general prediction was that place-related identifications with mountains will positively predict well-being associated with visiting these sites.

This suggests that mountain experiences might be viewed as elements of a person's identity (Borrie and Birzell, 2001; Clayton, 2003), meaning that favorite places might become intertwined with the self (Tuan, 1977; Knez, 2014). Accordingly, the self might practically recommend itself to visit favorite places to increase well-being in a self-reflective and self-regulating way (Korpela, 1989, 1992; Korpela and Hartig, 1996; Korpela et al., 2001; Knez, 2006), proposing that revisiting a favorite place might, in consequence, be considered as an affect-regulation strategy. Parkinson and Totterdell (1999) have indeed shown that visitinga- favorite-place is classified as an affect-regulation strategy. All this is in line with the theory of self-regulation, suggesting that we, by forethought (Bandura, 1991), monitor, regulate and advocate our behaviors proactively such as to minimize negative affect and to increase positive affect and health behavior (Carver and Scheier, 1990; Heatherton, 2011; Mann et al., 2013).

In addition, residents' reports of mountain-related activities were also collected, as well as perceptual and aesthetical values, cultural and historical identifiers associated with their personal and collective favorite sites. This was done because nature-related bonding involves multiple ways of, and activities connected with, appreciating nature (Hammitt et al., 2006; Brown and Raymond, 2007; Brügger et al., 2011; Hayden et al., 2015) providing health benefits (Pretty, 2004; Pretty et al., 2005). In addition, activities such as esthetic appreciation of natural landscapes, and recreation are categories of cultural ecosystem services that are 
provided by landscapes (Millenium Ecosystem Assessment [MA], 2005).

Finally and line with (1) Canli et al. (2000) and Phelps (2006) indicating that emotion may enhance and modulate better retention in autobiographical memory, (2) that emotion may regulate intrinsic psychological processes (Gross, 2010), and (3) that the emotional component may precede the cognitive one in place-identification because a favorite place might be easier recalled due to its emotional information (Knez, 2014), we predicted that emotional bonds would be stronger predictors of well-being than cognitive bonds in relation to both personal and collective favorite places.

\section{MATERIALS AND METHODS}

\section{Study Area}

The county of Jämtland is located at a latitude of $63^{\circ} \mathrm{N}$ in the northwest part of Sweden with the Scandinavian Mountains bordering Norway (see Figure 1). With its area of $49,443 \mathrm{~km}^{2}$, it is the third largest county in Sweden and comparable to the size of the Netherlands.

Jämtland has a diverse geography with old forests to the east, a rolling landscape in the central areas, and alpine massifs up to 1,797 meters above sea level (MASL) to the west. The climate is harsh with predominantly west winds and monthly mean temperatures of $-8^{\circ} \mathrm{C}$ in January and $13.5^{\circ} \mathrm{C}$ in July for the city of Östersund. The county has been an important tourism destination since the opening of the railway to Norway in the late 19th century. It also includes 12 Sami villages with the right to carry on reindeer husbandry.

\section{Sample}

A total of 2,700 households, proportionally and randomly distributed across eight municipalities, identified from a population register, were sent a "mountain survey." Participants were not offered any incentive for taking part in the survey, which involved 12 sections including both quantitative and qualitative questions. Data on mountain-related activities, values, cultural and historical identifiers, personal and collective placeidentity and well-being will be reported in this study. Finally, the survey was conducted in accordance with the ethical guidelines of the University of Gothenburg Sweden, in charge of the project; therefore, not reviewed and approved by any special ethic committee.

\section{Procedures, Response Rate and Demographic Statistics}

Surveys were distributed and returned by mail. After two contacts (a reminder was sent a week later) 850 responses (32\%) were achieved proportionally distributed across the eight municipalities, involving $51.7 \%$ women and $48.3 \%$ men. $44.9 \%$ of the participants were $18-55$ years old and $50.1 \% 56-80$ years old. The participants' mean residence time, living in Jämtland County, was 40.6 years (ranging from one to 79 years). Their educational background was distributed across three types of education: elementary education (19.4\%), upper secondary education (42.1\%) and university education (38.4\%). Most of participants were employed $(58.5 \%)$ or retirees $(30.1 \%)$. The questionnaire was fully anonymous.

\section{Measures}

What do you do when you are in the Jämtland County mountains? Participants were asked to estimate the frequency (how many times per year) of performing each one of the eighteen activities: Spirituality; Work; Berry and mushroom picking; Festival, exhibitions, markets; Outdoor recreation; Bird and wildlife watching; Health experiences; Hunting, fishing; Consumption, trade; Museums, historical sites; Nature and landscape; Fun and nightlife; Snowmobiling; Sports, sports activities; Socializing with friends/family; Tradition (family, culture); Education; Rest, leisure; Adventure. They were also asked to estimate the importance of each type of activity on a 7-point scale, ranging from 1 (little/not at all important) to 7 (very important). This measure was included because nature-related bonding involves multiple ways of appreciating nature (Hammitt et al., 2006; Brown and Raymond, 2007; Brügger et al., 2011). Additionally, we asked participants to estimate during which time of the year and how often they engaged in these activities, on a scale ranging from 1 to 5: daily (1); one to several times a week (2), one to several times a month (3), one to several times per season (4); more rarely/never (5).

Which five Jämtland County mountain sites are most important for you personally? By this we mean places that are your favorites; places which increase the understanding of who you are? This was a qualitative data question; participants were asked to write down the names of these places (or indicate on a map that was included in the survey). They were further asked to select one of the places which is most important for you personally (your favorite site) and answer the following questions about it: What do you value most about this place? What are the site's cultural and historical identifiers? Participants were asked to write down their responses. All this was repeated for: Which five Jämtland County mountain sites are important for you living in Jämtland; that is, places that enhance the understanding of the County's identity? (Note: plural form of "you" in Swedish is "er" and singular form is "dig"; hence, different words that connote directly to collective vs. personal dimensions of "you.")

This measure was included because collective memory is established both as internal (memory of the individual) and external (culturally and historically shared memory of the collective) reminiscence (Halbwachs, 1941/1992), revealed through individual autobiographies (Rigney, 2005; Assmann, 2008; Manier and Hirst, 2008). Previous research has also shown that places' cultural and historical dimensions might create a sense of continuity (Devine-Wright and Lyons, 1997; Rishbeth and Powell, 2013), as well as be related to place ties (Low, 1992; Lewicka, 2005).

\section{Place-Identity}

This measure involves an autobiographical emotional and a cognitive component comprising 10 statements 


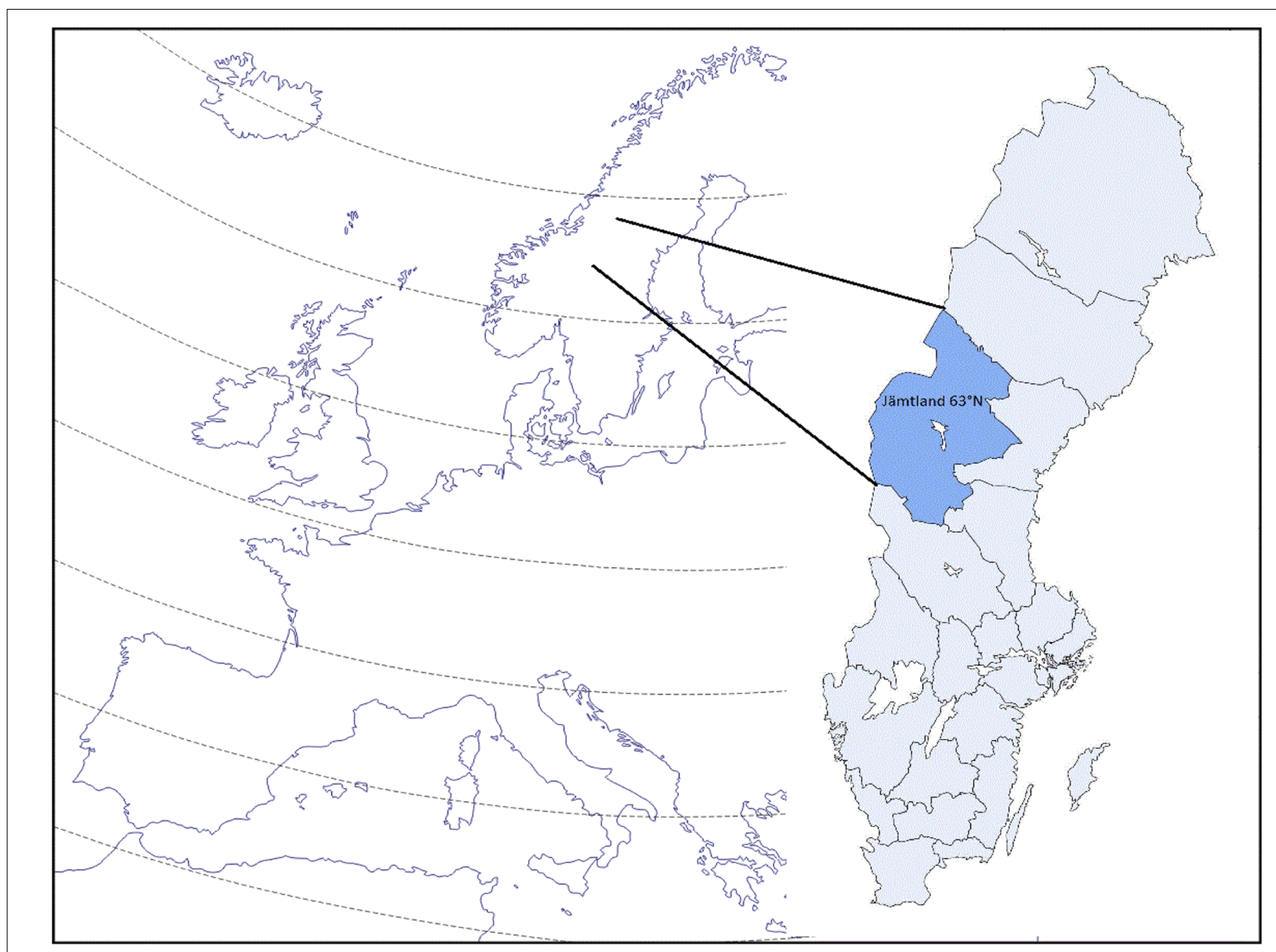

FIGURE 1 | The map of Europe and Sweden, with Jämtland county.

(Knez, 2014). Emotional component (processes of attachment/closeness/belonging; in the present study, with a Cronbach alpha of 0.91): "I know the place very well."; "I miss it when I'm not there."; "I have strong ties to the place."; "I am proud of the place."; "The place is a part of me." Cognitive component (processes of coherence, correspondence, mental temporality, reflection and agency; in the present study, with a Cronbach alpha of 0.92): "I have had a personal contact with this place over a long period."; "There is a link between the place and my current life."; "I can travel back and forth in time mentally to this place when I think about it."; "I can reflect on the memories attached to this place."; "These thoughts about the place are part of me." Participants were asked to respond to these statements on a 7-point scale ranging from 1 (completely disagree) to 7 (completely agree). This was the personal place identity measure. For the collective measure we changed the pronoun "I" to "we (living in the county of Jämtland)."

\section{Well-Being}

Participants were asked to respond to ten statements from "The WHO (10) well-being index" (Bech et al., 1996), measuring their place-related well-being. They responded to the question of when I'm on the site, I feel: "Sad and down" (R); "Calm and relaxed"; "Energetic, active and enterprising"; "Relaxed and refreshed"; "Happy and pleased with my personal life"; "Satisfied with my living situation"; "I live the life I want to live"; "Inspired to deal with today's work"; "I can cope with serious problems or changes in my life"; "That life is full of interesting things." Furthermore, the 4-point scale from the original measure was rearranged yielding a 7-point scale, ranging from 1 (completely disagree) to 7 (completely agree), with a Cronbach alpha of 0.91 .

\section{Design and Analyses}

Both qualitative (inductive thematic organization of the open question answers) and quantitative data (ANOVA and regression) analyses were performed, see Section "Results." The qualitative, inductive analysis "begins with specific observations and builds toward general patterns. Categories or dimensions of analysis emerge from open-ended observations as the inquirer comes to understand patterns that exist in the phenomenon being investigated" (Patton, 2002, pp. 55-56). 


\section{RESULTS}

The qualitative and quantitative data analyses are reported below in three sections: "mountain activities and season," "personal sites in mountains and well-being," and "collective sites in mountains and well-being."

\section{Mountain Activities and Season}

As can be seen in Figure 2, descriptive statistics showed that the four most frequent (number of times per year) mountain activities performed by the residents were "outdoor recreation" $(M=15.3, S D=55.15)$, "nature and landscape" $(M=12.37$, $S D=40.03)$, "rest and leisure" $(M=10.83, S D=40.79)$, and "socializing with friends/family" $(M=8.2, S D=30.86)$. These activities were also valued to be the four most important ones (see Figure 3); "outdoor recreation" $(M=4.83, S D=2.27)$, "nature and landscape" $(M=4.74, S D=2.34)$, "rest and leisure" $(M=4.26, S D=2.54)$, and "socializing with friends/family" $(M=4.17, S D=2.58)$. Thus, participants were shown to be consistent in judging frequency of their activities with their estimations of the importance of these activities.

Mountain activities were furthermore shown to be performed mostly during winter $(M=3.2, S D=1.33)$ and least during summer $(M=3.46, S D=1.38)$. In other words, residents were almost "one to several times a month" ( 3 on a 5-point scale) in the mountains and during summer they were there in between "one to several times a month" and "one to several times during the season" (4 on a 5-point scale) in the mountains.

\section{Personal Sites in Mountains and Well-Being}

The qualitative data analysis (participants' own words in “...") showed that $86 \%$ of residents pointed out 176 favorite sites in the mountains as the personally most important ones; $50 \%$ of these were mentioned only once. This indicates that half of the residents had settled an own favorite spot in the mountains. Most of these sites were in Åre (27\%), Ovik (18\%), West Jämtland (17\%), West Härjedalen (13\%), and Vemdalen/Lofsdalen (12\%) mountain areas. Based on three criteria (geology, communication and cultural heritage) these areas were characterized as follows:

(1) Åre mountains have been of great geological importance for the understanding of the plate tectonic theory. This is because shale layers at Mount Åreskutan (1420 MASL) are reversed which means that older layers are above younger ones. Åre has nearly 800,000 guest nights a year, mainly during the winter season December to April.

(2) Mountains in the Ovik area consist of quartzite and reach up to 1,400 MASL. The area is located close to the city of Östersund and its airport. The area is popular for skiing, hiking, fishing and hunting and includes two Natura 2000, EU nature protection areas.

(3) West Jämtland has a plateau character due to the huge overshoot of resistant bedrock consisting of shales rich in quartz, gneiss and amphibolies. Most of the mountains, however, reach up to 1,500 MASL. The area is appreciated for being a wilderness and inaccessible although it hosts Sami reindeer husbandry.

(4) Mountains in West Härjedalen reach up to 1,300 m MASL and the bedrock consists of resistant shales rich in quartz, gneiss and amphibolites. The tourist destination markets itself as Scandinavia’s largest ski area.

(5) Mountains in Vemdalen/Lofsdalen reach up to 1,200 MASL and consist of a quartzite bedrock that was formed during the Cambrian and Silurian, 542-416 million years ago. The area hosts the fourth largest winter sports destination in Sweden as, well as Sami villages and several mountain pastures of which some are farmed and some are classified as Natura 2000 EU nature protection areas.

What do you value most in this place? The five most valued attributes were: Landscape 19.5\% ("beautiful, wide vistas, views, terrain, towering mountain"); Outdoor restoration $13.5 \%$ ("relaxation, recreation, spirituality, freedom, silence, peace, and quiet"); Ease of use 13.5\% ("near where I live, day trips are possible, ski-in-ski-out"); Alpine 10\% ("skiing and slopes/ski resorts"); Undeveloped 7\% ("untouched, genuine mountain environment, wilderness, solitude, few people").

What are the site's cultural identifiers? The five most frequent categories were: Historic buildings 14.5\% ("settlements, settlements and churches"); Sami culture 13\% ("nest sites, chapels, reindeer husbandry"); Stories/local history 10\% ("about villages, towns, accommodation"); Natural sites $9 \%$ ("waterfalls, rivers, lakes, rivers, mountains, caves"); Industrial history 8\% ("mines, mills, sawmills").

What are the place's historical identifiers? The five most frequent categories were: the Carolean March (a historical warrelated march across the Jämtland mountains in1718) 19.5\%; Stories/local history 13\%; Industrial history 8.5\%; History of tourism 6.5\% ("visitors arriving by plane, spa resort, hotels and exploitation"); Infrastructure 6.5\% ("rail, roads, bridges, aerial tramway").

\section{Place-Related Identity and Well-Being}

The quantitative data (regression) analysis (including emotion and cognitive components as predictors, and wellbeing as criterion variable) showed that both components (emotion + cognition) of personal place-identity were positively associated with well-being (see Table 1). This means that the stronger the attachment/belonging/closeness (emotional component) residents felt to a favorite personal site in mountains the more well-being they perceived in that place. Similarly, the more remembrance, thinking and mental travel (cognitive component) residents directed to this site the more well-being they perceived in that place. However, and as predicted the emotion-wellbeing link compared to the cognition-wellbeing link was stronger (see Beta statistics in Table 1).

\section{Collective Sites in Mountains and Well-Being}

The qualitative data analysis (participants own words in “...") showed that $78 \%$ of respondents pointed out 91 collectively important sites in Jämtland; $70 \%$ of these were mentioned more 


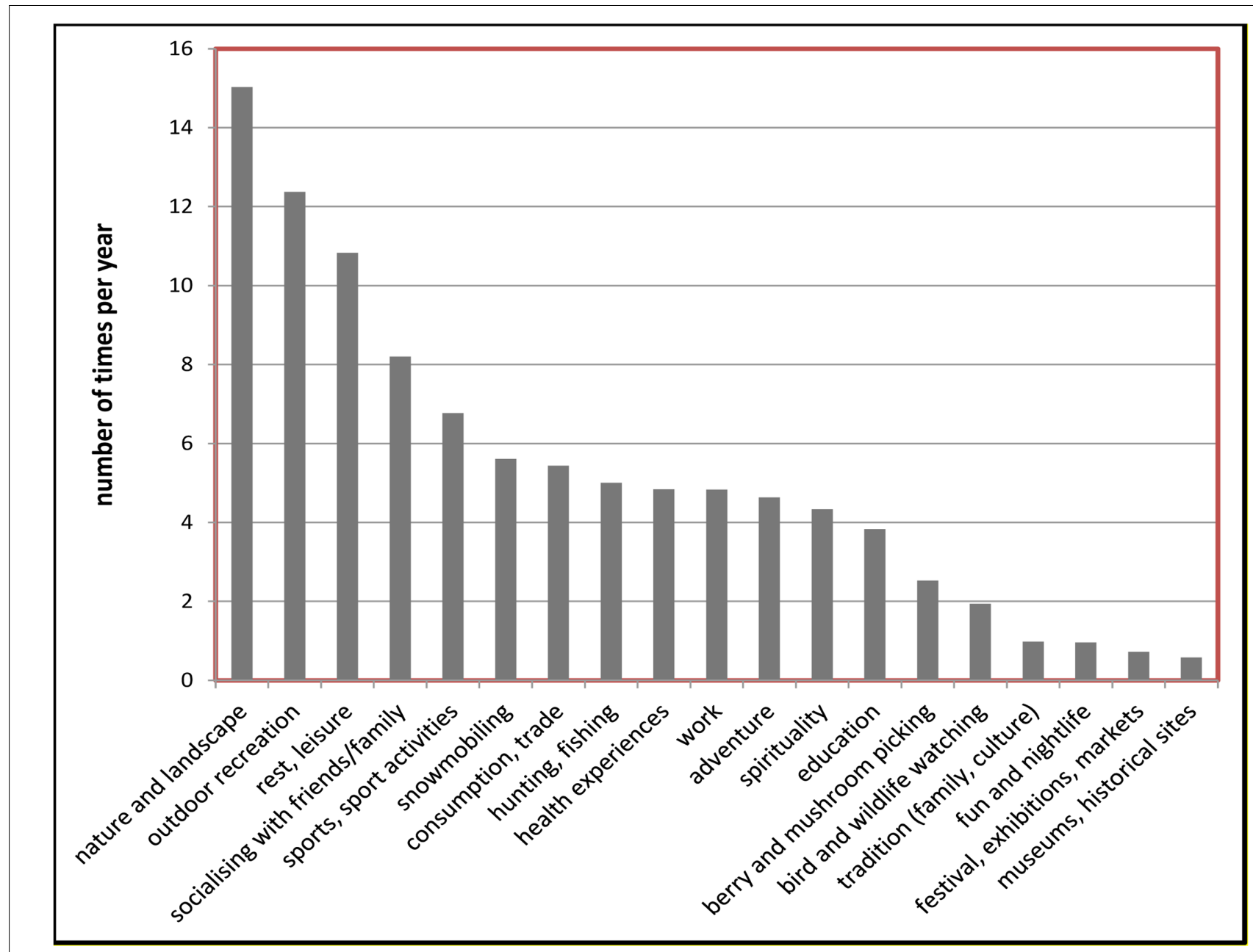

FIGURE 2 | Frequency (number of times per year) of nineteen types of mountain activities.

than once. Similarly, as above for personal sites, the majority of sites were in the Åre (29\%), Ovik (16\%), Vemdalen/Lofsdalen (15\%), West Härjedalen (13\%), and West Jämtland (12\%) mountains.

What do you value most in this place? The five most valued attributes were: Tourism, 21\% ("tourism, employments, branding of the county"); Alpine 16\%; Ease of use access 10.5\%; Landscape 10.5\%; Outdoor restoration 5.5\%.

What are the site's cultural identifiers? The five most frequent categories were: Tourism 13\%; Natural sites 11.5\%; Historic buildings 11.5\%; Stories/local history 9\%; Outdoor life 7.5\% ("hiking, skiing, mountain stations, mushroom-picking, berries, hunting and fishing”).

What are the place's historical identifiers? The five most frequent categories were: the Carolean March 30\%; History of tourism 10\%; Stories/local history 9\%; Sports 7.5\% ("World Cup, sports contests, sports events/stories); Infrastructure 6.5\%.

\section{Place-Related Identity and Well-Being}

The quantitative data (regression) analyses (including emotion and cognitive components as predictors, and well-being as criterion variable) showed similar results as above; namely, that both components (emotion + cognition) of collective placeidentity were positively related to well-being (see Table 1). Thus, the stronger the attachment/belonging/closeness (emotional component) residents felt to a favorite collective site in mountains the more well-being they perceived in that place. Similarly, the more remembrance, thinking and mental travel (cognitive component) residents directed to this site the more well-being they perceived in that place. However, and as predicted emotion component of place identity was a stronger predictor of wellbeing than cognition component of place-identity (see Beta statistics in Table 2).

\section{DISCUSSION}

The aim was to investigate the relationships between landscaperelated personal and collective identity and well-being of residents living in a mountain county. Residents' reports of mountain-related activities were also collected, as well as perceptual and aesthetical values, cultural and historical 


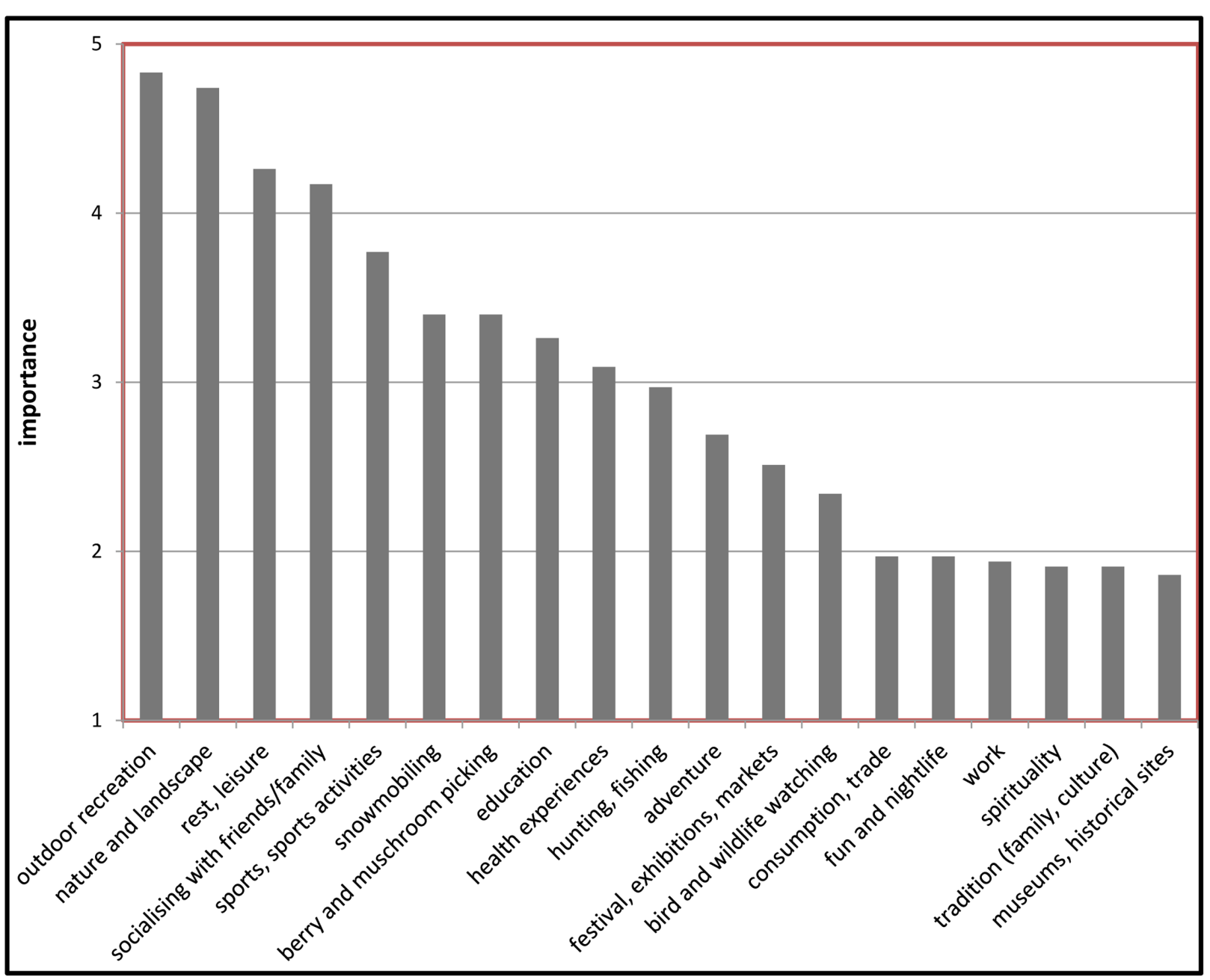

FIGURE 3 | Mean importance of nineteen types of mountain activities.

TABLE 1 | Regression statistics for the relation between personal place-identity (predictors: components of emotion and cognition) and well-being (criterion).

\begin{tabular}{llccccrr}
\hline $\boldsymbol{R}$ & Beta & SE & df & MS & $\boldsymbol{F}$ & Sig. & $\boldsymbol{t}$ \\
\hline 0.39 & 0.45 (emotion) & 0.04 & 2,756 & 179.3 & 244.4 & 0.00 & 8.19 \\
& 0.20 (cognition) & 0.03 & & & & & 0.00 \\
& & & & & & & 0.00
\end{tabular}

TABLE 2 | Regression statistics for the relation between collective place-identity (predictors: components of emotion and cognition) and well-being (criterion).

\begin{tabular}{|c|c|c|c|c|c|c|c|c|}
\hline$R$ & Beta & $S E$ & df & MS & $F$ & Sig. & $t$ & Sig. \\
\hline & 0.17 (cognition) & 0.04 & & & & & 3.49 & 0.00 \\
\hline
\end{tabular}

identifiers associated with their personal and collective favorite sites in mountains.

It was shown that residents' most frequent and most important activities, when visiting the mountains, were related to "outdoor recreation," "nature and landscape," "rest and leisure," and "socializing with friends/family." This is in line with previous research on self-regulation showing that people are active in using nature-related sites for emotional release and relaxation (Korpela, 1989, 1992; Korpela and Hartig, 1996; Knez, 2006), as well as for aesthetical (Brown and Raymond, 2007) and social (Hammitt et al., 2006) values; suggesting that nature engagement generate health benefits (Pretty, 2004; Pretty et al., 2005). Additionally, 
these behaviors were mostly performed during the winter/spring and least during the summer, due to the deep-rooted winteroutdoor culture in northern parts of Sweden.

Concerning personal favorite sites, $50 \%$ of residents were shown to settle on an own favorite site. In agreement with the above results and reasoning (Korpela, 1989, 1992; Korpela and Hartig, 1996; Hammitt et al., 2006; Knez, 2006; Brown and Raymond, 2007), the most valued attributes related to these favorite sites were aesthetical values of landscape and outdoor restoration experiences. The cultural and historical identifiers involved both built (settlements, nest sites, mills, bridges and roads) and natural dimensions (waterfalls, rivers, lakes, caves) as well as reindeer husbandry and local stories/history associated with these cultural and historical themes. This is in accord with previous research showing that places' cultural and historical dimensions may create a sense of continuity (Devine-Wright and Lyons, 1997; Rishbeth and Powell, 2013; Wheeler, 2014) and be linked to people-place ties (Low, 1992; Lewicka, 2005), suggesting that "legacies we inherit stem both from nature and from culture." (Lowenthal, 2005, p. 81).

It was also shown that the stronger the attachment/closeness/belonging residents felt to a favorite personal site in mountains the more well-being they perceived in that place. Similarly, the more remembrance, thinking and mental travel residents directed to this site the more well-being they perceived in that place. Thus both emotional and cognitive components of place-identification (Knez, 2014) were positively related to well-being. However, the emotion-wellbeing compared to cognition-wellbeing link was stronger. This is in line with our prediction that a favorite place might be easier cognitively operated due to its emotional content (Canli et al., 2000; Phelps, 2006; Gross, 2010; Knez, 2014). It is also, in general terms, in accordance with previous research suggesting positive relations between nature and health and well-being and between cultural ecosystem services of identity and well-being (Millenium Ecosystem Assessment [MA], 2005; Bowler et al., 2010; Abraham et al., 2010; Hartig et al., 2011; Lachowycz and Jones, 2013; Carrus et al., 2015; Sandifer et al., 2015).

This indicates that mountain experiences might be a part of respondents' place-related self (Knez, 2014). The fact that respondents revisit these most important favorite places in mountains suggests that these sites are in a sense recommended by the self in an affect- (Parkinson and Totterdell, 1999) and self-regulating way (Korpela, 1989, 1992; Korpela and Hartig, 1996; Knez, 2006). This is done in order to increase positive affect and health behaviors (Carver and Scheier, 1990; Mann et al., 2013); especially, because the emotional component of the place-related self was shown to link strongly to well-being (Gross, 2010). According to Parkinson and Totterdell (1999) a favorite place operates as an affect regulation strategy, suggesting that we advise ourselves proactively (Bandura, 1991) to increase positive affect and health behavior (Carver and Scheier, 1990; Heatherton, 2011; Mann et al., 2013) by going to a favorite place.

Concerning collective favorite places, the most valued attributes related to these sites were related to tourism and alpine activities; which is in accordance with the county's branding. The cultural and historical identifiers involved mostly tourism and outdoor life related dimensions as well as sport events. This suggests an episodic and semantic collective reminiscence, including a combination of shared collective experience (narrative) with "lived" (formed between generations) and "distant" (communicated by institutions) semantic memory (Manier and Hirst, 2008). Furthermore, and with regard to personal favorite sites, the stronger the attachment/closeness/belonging residents felt to a favorite collective site the more well-being they perceived in that place. Similarly, the more remembrance, thinking and mental travel residents directed to this site the more well-being they perceived in that place. Thus, collective favorite places were also advised, forethought (Bandura, 1991), by the self to revisit, to increase well-being in a self-regulating way (Parkinson and Totterdell, 1999); but as for personal sites the emotion-wellbeing compared to cognition-wellbeing link was stronger.

\section{CONCLUSION}

Our results have shown that mountain county residents have individually and collectively pinpointed their favorite sites in mountains to which they have evolved emotional and cognitive bonds, meaning that these locations are part of their personal and collective memory and their life-story (Knez, 2014). When visiting these places they enjoy outdoor recreation/restoration, viewing and experiencing nature and landscape, rest and leisure, and perceive higher levels of well-being; thus, implying a "healthy nature healthy people" relation (Maller et al., 2005). A stronger relationship between the emotional than the cognitive bond of place-identity with well-being was, however, reported, indicating that emotion may enhance, modulate and regulate better these intrinsic psychological processes (Canli et al., 2000; Phelps, 2006; Gross, 2010). All this is in line with previous research indicating (1) positive associations between nature and human health and well-being (Pretty, 2004; Hartig et al., 2011), (2) transcendent experience in nature involving positive affect (Williams and Harvey, 2001), and (3) that cultural ecosystem services of landscape-identifications may enhance well-being (Millenium Ecosystem Assessment [MA], 2005). Finally, what are the practical implications of the results obtained? Our results highlight the importance of person-place bonds not only to urban green spaces (e.g., Gunnarsson et al., 2016; Ode Sang et al., 2016), but also to rural sites and their inhabitants. Given that going to a favorite place is a type of affect-regulation strategy that we use in order to monitor and improve our feelings (Parkinson and Totterdell, 1999), we conclude with Carl von Linnés selfbiographical reflections from the year of 1732 (Linné, 1811, pp. 109-110): "As soon as I reached the mountains I felt reborn and that a heavy burden had been lifted from me."

\section{AUTHOR CONTRIBUTIONS}

All authors listed, have made substantial, direct and intellectual contribution to the work, and approved it for publication. 


\section{FUNDING}

This study was part of the project "Mountain landscape the importance of cultural ecosystem services" which was supported financially by the Swedish National Heritage Board and the Swedish Environmental Protection Agency within the research initiative "A magnificent mountain landscape." Cofinancing was also received from the County Administrative

\section{REFERENCES}

Abraham, A., Sommerhalder, K., and Abel, T. (2010). Landscape and well-being: a scoping study on the health-promoting impact of outdoor environments. Int. J. Public Health 55, 59-69. doi: 10.1007/s00038-009-0069-z

Ainsworth, M. D. S., Blehar, M. C., Waters, E., and Wall, S. (1978). Patterns of Attachment: A Psychological Study of the Strange Situation. Hillsdale, NJ: Erlbaum.

Aplin, G. (2007). World heritage cultural landscapes. Int. J. Herit. Stud. 6, 427-446. doi: $10.1080 / 13527250701570515$

Assmann, J. (2008). “Communicative and cultural memory," in Cultural Memory Studies: An International and Interdisciplinary Handbook, eds A. Erll and A. Nünning (Berlin: de Gruyter), 109-118.

Bandura, A. (1991). Social cognitive theory of self-regulation. Organ. Behav. Hum. Decis. Process. 50, 248-287. doi: 10.1016/0749-5978(91)90022-L

Bech, P., Gudex, C., and Staeher Johansen, K. (1996). The WHO (Ten) well-being index: validation in diabetes. Psychoter. Psychosom. 65, 183-190. doi: 10.1159/ 000289073

Bolam, B., Murphy, S., and Gleeson, K. (2006). Place-identity and geographical inequalities in health: a qualitative study. Psychol. Health 21, 399-420. doi: $10.1080 / 14768320500286526$

Borrie, W., and Birzell, R. M. (2001). "Approaches to measuring quality of the wilderness experience," in Proceedings of the RMRSP-20: Visitor Use Density and Wilderness Experience, eds W. A. Freimund and D. N. Cole (Ogden, UT: US Department of Agriculture, Forest Service, Rocky Mountain Research Station), 29-38.

Bowler, D. E., Buyung-Ali, L. M., Knight, T. M., and Pullin, A. S. (2010). A systematic review of evidence for the added benefits to health exposure to natural environments. BMC Public Health 10:466. doi: 10.1186/1471-245810-456

Bragg, E. A. (1996). Towards ecological self: deep ecology meets constructionst self-theory. J. Environ. Psychol. 16, 93-108. doi: 10.1006/jevp.19 96.0008

Bratman, G. N., Daily, G. C., Levy, B. J., and Gross, J. J. (2015). The benefits of nature experience: improved affect and cognition. Landsc. Urban Plan. 138, 41-50. doi: 10.1016/j.landurbplan.2015.02.005

Brown, G., and Raymond, C. (2007). The relationship between place attachment and landscape values: toward mapping place attachment. Appl. Geogr. 27, 89-111. doi: 10.1016/j.apgeog.2006.11.002

Brügger, A., Kaiser, F. G., and Roczen, N. (2011). One for all: connectedness to nature, environmental identity, and implicit association with nature. Eur. Psychol. 16, 324-333. doi: 10.1027/1016-9040/a000032

Canli, T., Zhao, Z., Brewer, J., Gabrielli, J. D., and Cahill, L. (2000). Event-related activation in the human amygdale associates with lateral memory for individual emotional experience. J. Neurosci. 20:RC99.

Canter, D. (1997). "The facets of place," in Advances in Environment, Behavior, and Design, eds G. T. Moore and R. W. Marams (New York, NY: Plenum Press).

Carrus, G., Scopelliti, M., Lafortezza, R., Colangelo, G., Ferrini, F., Salbitano, F., et al. (2015). Go greener, feel better? The positive effects of biodiversity on the well-being of individuals visiting urban and peri-urban green areas. Landsc. Urban Plan. 134, 221-228. doi: 10.1089/cyber.2013.0157

Carver, C. S., and Scheier, M. F. (1990). Origins and functions of positive and negative affect: a control-process view. Psychol. Rev. 1, 19-35. doi: 10.1037/ 0033-295X.97.1.19

Casey, E. S. (2000)). Remembering: A Phenomenological Study, 2nd Edn. Bloomington, IN: Indiana University Press.
Board of Jämtland, University of Gothenburg and University of Gävle.

\section{ACKNOWLEDGMENT}

We would like to thank the two reviewers for their constructive and valuable comments.

Chan, K. M. A., Guerry, A. D., Balvanera, P., Klain, S., Satterfield, T., Basurto, X., et al. (2012). Where are cultural and social ecosystem services? A framework for constructive engagement. Bioscience 8, 744-756.

Clayton, S. (2003). "Environmental identity: a conceptual and an operational definition," in Identity and the Natural Environment, eds S. Clayton and S. Opotow (Cambridge, MA: MIT Press), 45-65.

Clayton, S. (2012). "Environment and identity," in The Oxford Handbook of Environmental and Conservation Psychology, ed. S. Clayton (New York, NY: Oxford University Press), 164-180.

Conway, M. (2005). Memory and the self. J. Mem. Lang. 53, 594-628. doi: 10.1016/ j.jml.2005.08.005

Conway, M. A., Singer, J. A., and Tagini, A. (2004). The self and autobiographical memory: correspondence and coherence. Soc. Cogn. 22, 495-537. doi: 10.1521/ soco.22.5.491.50768

Daily, G. C., Polasky, S., Goldstein, J., Karieva, P. M., Mooney, H. A., Pejchar, L., et al. (2009). Ecosystem services in decision making: time to deliver. Front. Ecol. Environ. 7, 21-28. doi: 10.1016/j.jenvman.2014.09.003

Daniel, T. C., Muhar, A., Arnberger, A., Aznar, O., Boyd, J. W., Chan, K. M. A., et al. (2012). Contributions of cultural services to the ecosystem services agenda. Proc. Natl. Acad. Sci. U.S.A. 23, 8812-8819. doi: 10.1073/pnas.11147 73109

Devine-Wright, P., and Lyons, E. (1997). Remembering pasts and representing places: the construction of national identities in Ireland. J. Environ. Psychol. 17, 33-45. doi: 10.1006/jevp.1996.0037

Droseltis, O., and Vignoles, V. L. (2010). Towards an integrative model of place identification: dimensionality and predictors of intra-personal place preferences. J. Environ. Psychol. 30, 23-34. doi: 10.1016/j.jenvp.2009.05.006

Dutcher, D., Finley, J., Luloff, A., and Johnson, R. (2007). Connectedness with nature as a measure of environmental values. Environ. Behav. 39, 474-493. doi: $10.1177 / 0013916506298794$

Erll, A. (2011). Memory in Culture. Hampshire: Palgrave Macmillan Memory Studies.

European Landscape Convention [ELC] (2000). European Landscape Convention. Strasbourg: Council of Europe, Directorate of Culture and Cultural and Natural.

Fivush, R. (2008). Remembering and reminiscing: how individual lives are constructed in family narratives. Mem. Stud. 1, 45-54. doi: 10.1080/00207594. 2011.596541

Gallagher, W. (1994). The Power of Place. New York, NY: Harper Perennial.

Gee, K., and Burkhard, B. (2010). Cultural ecosystem services in the context of offshore wind farming: a case study from the west coast of Schleswig-Holstein. Ecol. Complex. 7, 349-358. doi: 10.1016/j.ecocom.2010. 02.008

Gesler, W. (2000). Hans Castorp's journey-to-knowledge of disease and health in Thomas Mann's The Magic Mountain. Health Place 6, 125-134. doi: 10.1016/ S1353-8292(00)00007-1

Graumann, C. F. (2002). "The phenomenological approach to people-environment studies," in Handbook of Environmental Psychology, eds R. B. Bechtel and A. Churchman (New York, NY: John Wiley \& Sons).

Grêt-Regamey, A., Brunner, S. A., and Kienast, F. (2012). Mountain ecosystem services: who cares? Mt. Res. Dev. 32, 23-34. doi: 10.1659/MRD-JOURNALD-10-00115.S1

Griffin-Pierce, T. (1997). When I am lonely the mountains call me: the impact of sacred geography on Navajo psychological well-being. Am. Indian Alsk. Native Ment. Health Res. 3, 1-10. doi: 10.5820/aian.0703.1997.1

Gross, J. J. (2010). "Emotion regulation," in Handbook of Emotions, eds M. Lewis, J. M. Haviland-Jones, and L. Feldman Barrett (New York, NY: The Guilford Press), 497-512. 
Gunnarsson, B., Knez, I., Hedblom, M., and Sang, $\AA$ (2016). Effects of biodiversity and environment-related attitude on perception of urban green space. Urban Ecosyst. doi: 10.1007/s11252-016-0581-x

Halbwachs, M. (1941/1992). On Collective Memory, trans. L. Coser. Chicago, IL: University of Chicago Press.

Hammitt, W. E., Backlund, E. A., and Bixler, R. D. (2006). Place bonding for recreation places: conceptual and empirical development. Leisure Stud. 25, 17-41. doi: 10.1080/02614360500098100

Hartig, T., Berg van, A. E., Hagerhall, C. M., Tomalak, M., Bauer, N., Hansmann, R., et al. (2011). "Health benefits of nature experience: psychological, Social and cultural processes," in Forests, Trees, and Human Health, eds K. Nilsson, M. Sangster, C. Gallis, T. Hartig, S. Vries de, K. Seeland, et al. (Berlin: Springer), 127-168.

Hayden, L., Cadenasso, M. L., Haver, D., and Oki, L. R. (2015). Residential landscape aesthetics and water conservation best management practices: homeowner perceptions and preferences. Landsc. Urban Plan. 144, 1-9. doi: 10.1016/j.landurbplan.2015.08.003

Heatherton, T. F. (2011). Neuroscience of self and self-regulation. Annu. Rev. Psychol. 62, 363-390. doi: 10.1146/annurev.psych.121208.131616

Hébert, I.-M. (2014). "Mountain reflections: reverence for the consciousness of nature," in Ecospychology, Phenomenology, and Environment, The Experience of Nature, eds D. A. Vakoch and F. Castrillón (New York, NY: Springer Science + Business Media), 27-46.

Hernández-Morcillo, M., Plieninger, T., and Bieling, C. (2013). An empirical review of cultural ecosystem services indicators. Ecol. Indic. 29, 434-444. doi: 10.1016/j.ecolind.2013.01.013

Hogg, M. (2006). "Social identity theory," in Contemporary Social Psychological Theories, ed. P. J. Burke (Palo Alto, CA: Standford University Press), 111-136. James, W. (1890/1950). The Principles of Psychology. New York, NY: Dover.

Jorgensen, B. S., and Stedman, R. C. (2001). Sense of a place as an attitude: lakeshore owners' attitudes toward their properties. J. Environ. Psychol. 21, 233-248. doi: 10.1006/jevp.2001.0226

Jorgensen, B. S., and Stedman, R. C. (2006). A comparative analysis of predictors of sense of place dimensions: attachment to, dependence on, and identification with lakeshore properties. J. Environ. Psychol. 3, 233-248.

Kaplan, S. (1995). The restorative benefits of nature: toeard and integrative framework. J. Environ. Psychol. 15, 169-182. doi: 10.1016/0272-4944(95) 90001-2

Kihlstrom, J. F., and Klein, S. B. (1994). "The self as a knowledge structure," in Handbook of Social Cognition, Vol. 1, eds R. S. Wyer and T. K. Srull (Hillsdale, NJ: Erlbaum), 153-208.

Klein, S. B. (2013). Making the case that episodic recollection is attributable to operations occurring at retrieval than to content stored in a dedicated subsystem of long-term memory. Front. Behav. Neurosci. 7:3. doi: 10.3389/ fnbeh.2013.00003

Klein, S. B., German, T. P., Cosmides, L., and Gabriel, R. (2004). A theory of autobiographical memory: necessary components and disorders resulting from their loss. Soc. Cogn. 5, 460-490. doi: 10.1521/soco.22.5.460.50765

Knez, I. (2005). Attachment and identity as related to a place and its perceived climate. J. Environ. Psychol. 25, 207-218. doi: 10.1016/j.socscimed.2017.01.009

Knez, I. (2006). Autobiographical memories for places. Memory 14, 359-377. doi: $10.1080 / 09658210500365698$

Knez, I. (2013). How concerned, afraid and hopeful are we? Effects of egoism and altruism on climate change related issues. Psychology 10, 744-752. doi: 10.4236/psych.2013.410106

Knez, I. (2014). Place and the self: an autobiographical memory synthesis. Philos. Psychol. 2, 164-192. doi: 10.3390/nu7115441

Knez, I. (2016a). Is climate change a moral issue? Effects of egoism and altruism on pro-environmental behavior. Curr. Urban Stud. 4, 157-174. doi: 10.4236/cus. 2016.42012

Knez, I. (2016b). Towards a model of work-related self: a narrative review. Front. Psychol. 7:331. doi: 10.3389/fpsyg.2016.00331

Knez, I., and Thorsson, S. (2006). Influences of culture and environmental attitude o thermal, emotional and perceptual evaluations of a square. Int. J. Biometeorol. 50, 258-268. doi: 10.1007/s00484-006-0024-0

Knez, I., and Thorsson, S. (2008). Thermal, emotional and perceptual evaluations of a park: cross-cultural, and environmental attitude comparisons. Build. Environ. 43, 1483-1490. doi: 10.1016/j.buildenv.2007.08.002
Knez, I., Thorsson, S., and Eliasson, I. (2013). Climate change: concerns, beliefs, and emotions in residents, experts, decision makers, tourists, and tourist industry. Am. J. Clim. Change 2, 254-269. doi: 10.4236/ajcc.2013.24025

Knez, I., Thorsson, S., Eliasson, I., and Lindberg, F. (2009). Psychological mechanisms in outdoor place and weather assessment: towards a conceptual model. Int. J. Biometeorol. 53, 101-111. doi: 10.1007/s00484-008-0194-z

Korpela, K. M. (1989). Place-identity as a product of environmental selfregulation. J. Environ. Psychol. 9, 241-256. doi: 10.1016/S0272-4944(89) 80038-6

Korpela, K. M. (1992). Adolescents' favorite places and environmental selfregulation. J. Environ. Psychol. 12, 249-258. doi: 10.1016/S0272-4944(05) 80139-2

Korpela, K. M. (2012). "Place attachment," in The Oxford Handbook of Environmental and Conservation Psychology, ed. S. D. Clayton (Oxford, NY: Oxford University Press), 148-163.

Korpela, K. M., and Hartig, T. (1996). Restorative qualities of favorite places. J. Environ. Psychol. 16, 221-233. doi: 10.1006/jevp.1996.0018

Korpela, K. M., Hartig, T., Kaiser, F. G., and Fuhrer, U. (2001). Restorative experience and self-regulation in favorite places. Environ. Behav. 33, 572-589. doi: 10.1016/j.amepre.2009.01.022

Lachowycz, K., and Jones, A. P. (2013). Towards a better understanding of the relationship between greenspace and health: development of a theoretical framework. Landsc. Urban Plan. 118, 62-69. doi: 10.1016/j.landurbplan.2012. 10.012

Laski, M. (1961). Ecstacy: A Study of Some Secular and Religious Experiences. London: The Cressett Press.

Leary, M. R., and Tangney, J. P. (eds) (2003). Handbook of Self and Identity. New York, NY: The Guilford Press.

Lewicka, M. (2005). Ways to make people active: role of place attachment, cultural capital, and neighborhood ties. J. Environ. Psychol. 4, 381-395. doi: 10.1016/j. jenvp.2005.10.004

Lewicka, M. (2008). Place attachment, place identity, and place memory: restoring forgotten city past. J. Environ. Psychol. 28, 209-231. doi: 10.1016/j.jenvp.2008. 02.001

Linné, C. V. (1811). Lachesis Lapponica: A Tour in Lapland. Published by Tr. James Edward Smith. London: White and Cochrane.

Low, S. M. (1992). "Symbolic ties that bind: place attachment and the plaza," in Place Attachment, eds I. Altman and S. M. Low (New York, NY: Plenum Press), 165-185.

Lowenthal, D. (2005). Natural and cultural heritage. Int. J. Herit. Stud. 1, 81-92. doi: $10.1080 / 13527250500037088$

Maller, C., Townsend, M., Pryor, A., Brown, P., and St Leger, L. (2005). Healthy nature healthy people: "contact with nature" as an upstream health promotion intervention for populations. Health Promot. Int. 1, 45-54. doi: 10.1093/heapro/ dai032

Manier, D., and Hirst, W. (2008). "A cognitive taxonomy of collective memories," in Cultural Memory Studies: An International and Interdisciplinary Handbook, eds A. Erll and A. Nünning (Berlin: de Gruyter), 253-262.

Mann, T., de Ridder, D., and Fujita, K. (2013). Self-regulation of health behavior: social psychological approaches to goal setting and goal striving. Health Psychol. 5, 487-498. doi: 10.1037/a0028533

Marris, P. (1982). "Attachment and society," in The Place Attachment in Human Behavior, eds C. M. Parker and J. Stevenson-Hinde (London: Tavistock Publications), 185-201.

Mayer, F. S., and Frantz, C. M. (2004). The connectedness to nature scale: a measure of individuals' feeling in community with nature. J. Environ. Psychol. 24, 503-515. doi: 10.1016/j.jenvp.2004.10.001

McConnell, A. R. (2011). The multiple self-aspects framework: self-concept representation and its implications. Pers. Soc. Psychol. Rev. 1, 3-27. doi: 10.1177/ 1088868310371101

Millenium Ecosystem Assessment [MA] (2005). Ecosystems and Human WellBeing: Synthesis. Washington, DC: Island Press.

Neisser, U. (1988). Five kinds of self-knowledge. Philos. Psychol. 1, 35-59. doi: $10.1080 / 09515088808572924$

Ode Sang, ̊̊, Knez, I., Gunnarsson, B., and Hedblom, M. (2016). The effects of naturalness, gender, and age on how urban green space is perceived and used. Urban For. Urban Greening 18, 268-276. doi: 10.1016/j.ufug.2016. 06.008 
Park, B.-J., Furuya, K., Kasetani, T., Takayama, N., Kagawa, T., and Miyazaki, Y. (2011). Relationship between psychological responses and physical environments in forest settings. Landsc. Urban Plan. 102, 24-32. doi: 10.1016/j.landurbplan.2011.03.005

Parkinson, R., and Totterdell, P. (1999). Classifying affect-regulation strategies. Cogn. Emot. 13, 277-303.

Patton, M. Q. (2002). Qualitative Research \& Evaluation Methods. London: Sage Publications.

Phelps, E. A. (2006). Emotion and cognition: insights from studies of the human amygdala. Annu. Rev. Psychol. 57, 27-53. doi: 10.1146/annurev.psych. 56.091103.070234

Pretty, J. (2004). How nature contributes to mental and physical health. Spiritual. Health Int. 2, 68-78. doi: 10.1002/shi.220

Pretty, J., Barton, J., Bharucha, Z. P., Bragg, R., Pencheon, D., Wood, C., et al. (2015). Improving health and well-being independently of GDP: dividends of greener and prosocial economies. Int. J. Environ. Helath Res. 11, 1-26. doi: 10.1080/09603123.2015.1007841

Pretty, J., Peacock, J., Sellens, M., and Griffin, M. (2005). The mental and physical outcomes of green exercise. Int. J. Environ. Health Res. 5, 319-337. doi: 10.1080/ 09603120500155963

Rigney, A. (2005). Plenitude, scarcity, and the circulation of cultural memory. J. Eur. Stud. 35, 11-28. doi: 10.1177/0047244105051158

Rishbeth, C., and Powell, M. (2013). Place attachment and memory: landscapes of belonging as experienced post-migration. Landsc. Res. 2, 160-178. doi: 10.1080/ 01426397.2011.642344

Russell, K. C. (2012). “Therapeutic use of nature," in Identity and the Natural Environment, eds S. Clayton and S. Opotow (Cambridge, MA: MIT Press), 428-444.

Sandifer, P. A., Sutton-Grier, A. E., and Ward, B. P. (2015). Exploring connections among nature, biodiversity, ecosystem services, and human health and wellbeing: opportunities to enhance health and biodiversity conservation. Ecosyst. Serv. 12, 1-5. doi: 10.1016/j.ecoser.2014.12.007

Scannell, L., and Gifford, R. (2010). Defining place attachment: a tripartite organizing framework. J. Environ. Psychol. 30, 1-10. doi: 10.1016/j.jenvp.2009. 09.006

Schaich, H., Bieling, C., and Plieninger, T. (2010). Linking ecosystem services with cultural landscape research. Gaia Ecol. Perspect. Sci. Soc. 19, 269-277.

Schultz, P. W. (2002). "Inclusion with nature: understanding the psychology of human-nature interactions," in The Psychology of Sustainable Development, eds P. Schmuck and P. W. Schultz (New York, NY: Kluwer), 61-78.

Stajkovic, A. (2006). Development of a core confidence-higher order construct. J. Appl. Psychol. 6, 1208-1224. doi: 10.1037/0021-9010.91.6.1208

Stobbelaar, D. J., and Pedroli, B. (2011). Perspectives on landscape identity: a conceptual challange. Landsc. Res. 3, 321-339. doi: 10.1080/01426397.2011. 564860
Taylor, S. (2010). Narratives of Identity and Place. London: Routledge.

Tengberg, A., Fredholm, S., Eliasson, I., Knez, I., Saltzman, K., and Wetterberg, O. (2012). Cultural ecosystem services provided by landscapes: assessment of heritage values and identity. Ecosyst. Serv. 2, 14-26. doi: 10.1016/j.ecoser.2012. 07.006

Thompson, C. W. (2011). Linking landscape and health: the recurring theme. Landsc. Urban Plan. 99, 187-195. doi: 10.1016/j.landurbplan.2010. 10.006

Thomsen, D. K. (2009). There is more to life story than memories. Memory 17, 445-457. doi: 10.1080/09658210902740878

Triandis, H. C. (1994). Culture and Social Behavior. New York, NY: McGraw-Hill.

Tuan, Y. (1977). Space and Place: The Perspective of Experience. Minneapolis, MT: University of Minnesota Press.

Tulving, E. (2002). “Chronesthesia: awareness of subjective time," in Principles of Frontal Lobe Function, eds D. T. Stuss and R. C. Knight (New York, NY: Oxford University Press), 311-325.

Turner, M. G. (1989). Landscape ecology: the effect of pattern on process. Annu. Rev. Ecol. Syst. 20, 171-197. doi: 10.1146/annurev.ecolsys.20.1.171

Ulrich, R. S. (1983). "Aesthetic and affective response to natural environments," in Human Behavior and Environment, eds I. Altman and J. F. Wohlwill (New York, NY: Plenum Press), 85-125.

Wang, Q. (2006). Earliest recollections of self and others in European, American, and Taiwanese young adults. Psychol. Sci. 17, 708-714.

Wang, Q. (2008). On the cultural constitution of collective memory. Memory 16, 305-317. doi: 10.1080/09658210701801467

Wheeler, R. (2014). Mining memories in a rural community: landscape, temporality and place identity. J. Rural Stud. 36, 22-32. doi: 10.1016/j.jrurstud. 2014.06.005

Williams, K., and Harvey, D. (2001). Transcedent experience in forest environments. J. Environ. Psychol. 21, 249-260. doi: 10.1006/jevp.2001.0204

Conflict of Interest Statement: The authors declare that the research was conducted in the absence of any commercial or financial relationships that could be construed as a potential conflict of interest.

The reviewer ER and handling Editor declared their shared affiliation, and the handling Editor states that the process nevertheless met the standards of a fair and objective review.

Copyright (c) $2017 \mathrm{Knez}$ and Eliasson. This is an open-access article distributed under the terms of the Creative Commons Attribution License (CC BY). The use, distribution or reproduction in other forums is permitted, provided the original author(s) or licensor are credited and that the original publication in this journal is cited, in accordance with accepted academic practice. No use, distribution or reproduction is permitted which does not comply with these terms. 